\section{UNIDADES LOCALES PARA LA GESTIÓN INTEGRAL DEL HÁBITAT. EXPERIENCIA CUBANA ${ }^{1}$}

Dania González Couret ${ }^{2}$

Norberto Álvarez Pequeño ${ }^{3}$

Odalia Águila Fleites ${ }^{4}$

Deremis Pérez Aguilera ${ }^{5}$

\section{Resumen}

La participación de la población en la conformación de su hábitat reporta ventajas económicas, sociales y ambientales, pero debe ser adecuadamente gestionada para garantizar la calidad de los resultados, lo cual requiere de estructuras organizativas apropiadas. El presente trabajo expone los resultados de una experiencia aplicada en la ciudad de Ciego de Ávila, que se inscribe dentro de las tendencias hacia una mayor descentralización y un incremento de la participación popular en la producción del hábitat que se propone hoy la Política de Vivienda en Cuba.

La investigación parte de la experiencia nacional e internacional para identificar las variables de la

\section{LOCAL UNITS FOR INTEGRAL HABITAT MANAGEMENT. THE CUBAN EXPERIENCE ${ }^{1}$}

\author{
Dania González Couret ${ }^{2}$ \\ Norberto Álvarez Pequeño 3 \\ Odalia Águila Fleites ${ }^{4}$ \\ Deremis Pérez Aguilera 5
}

\begin{abstract}
The participation of people in the formation of their habitat implies economic, social and environmental advantages; however, this participation should be carefully managed through proper entities in order to ensure the quality of results. This article presents the case of Ciego de Ávila, which reveals decentralization trends and an increase of popular participation in the production of habitat promoted by Cuban Housing Policies.
\end{abstract}

This research analyzes national and international experiences and identifies 
gestión como independientes y las de la calidad del hábitat como dependientes. Sobre la base de un diagnóstico de la calidad del hábitat y las insuficiencias en su gestión, elabora una propuesta de nuevo modelo para la gestión integral del hábitat a nivel local, lo implementa en tres zonas urbanas de la ciudad seleccionadas como objeto de estudio y evalúa el impacto positivo de los resultados de su aplicación, tanto en el medio físico como en la satisfacción de la población.

PALABRAS CLAVE: VIVIENDA, GESTIÓN, PARTICIPACIÓN Y CALIDAD DEL HÁBITAT.

Fecha de recepción: 07.03.11.

Fecha de aceptación: 10.06.11.

1 Proyecto de investigación “Gestión participativa de la vivienda en Cuba", financiada por el Ministerio de la Construcción de Cuba entre 2008-2010.

2 Cuba. Directora de Posgrado, Instituto Superior Politécnico José Antonio Echeverría (ISPJAE), La Habana. Correo Electrónico:daniagc@tesla.cujae.edu.cu

3 Cuba. Director Unidad Provincial Inversionista de la Vivienda en Ciego de Ávila. Correo Electrónico: norbertoap@enet.cu

4 Cuba. Unidad Provincial Inversionista de la Vivienda en Ciego de Ávila.Correo Electrónico: upiveco@enet.cu

5 Cuba. Unión Provincial Inversionista de la Vivienda en Ciego de Ávila. Correo Electrónico: upiveco@enet.cu management variables as independent factors and housing quality variables as dependent factors. By diagnosing housing quality and its management weaknesses, this article proposes a new model for integral housing management at a local level that is applied in three urban areas of the selected city and assesses positive results at physical and satisfaction levels.

\section{KEYWORDS: HOUSING, MANAGEMENT, PARTICIPATION AND HOUSING QUALITY.}

Received: 07.03.11.

Accepted: 10.06.11.

1 Research Project "Participatory Management of Housing in Cuba", funded by the Ministry of Construction, 2008-2010

2 Cuban. Postgraduate Director, Instituto Superior Politécnico José Antonio Echeverría (ISPJAE), Havana. Email: daniagc@ tesla.cujae.edu.cu

3 Cuban. Director, Housing Investment Unit, Ciego de Ávila. Email: norbertoap@enet.cu

4 Cuban. Housing Investment Unit, Ciego de Ávila. Email: upiveco@enet.cu

5 Cuban. Housing Investment Unit, Ciego de Ávila. Email: upicevo@enet.cu 


\section{Introducción}

El Índice de Desarrollo Humano usado por el PNUD se calcula a partir de tres dimensiones fundamentales: esperanza de vida al nacer, conocimientos e ingresos ${ }^{6}$. Sin embargo, recientemente se ha propuesto el Índice de Desarrollo Socio-Habitacional (IDSH) como forma de medir la dimensión habitacional del Desarrollo Humano ${ }^{7}$, y así reconocer el "Derecho Humano a Vivienda Adecuada" incluido dentro de los Derechos Económicos, Sociales y Culturales (DESC) $)^{8}$ y el "Derecho a la Ciudad"

La tendencia actual de las políticas de vivienda en la región latinoamericana ha rebasado el estrecho marco de la preocupación por la cantidad, para centrar su atención también en la calidad de la vivienda, de lo cual son expresión lemas como el de Bolivia, "La vivienda: un lugar donde vivir bien"10, o Chile, "El buen vivir"11. Estas prioridades quedan recogidas en los derechos reconocidos a la ciudad y a una vivienda adecuada.

También dentro de la Coalición Internacional Hábitat - América Latina se ha ido construyendo el concepto de "producción social del hábitat y la

\footnotetext{
6 Pichs, Madruga, Ramón, 2008.

7 Rodríguez Cáceres, Gustavo Marcelo, 2008

8 Por el derecho humano a la vivienda, 2008

9 Carta Mundial por el derecho a la ciudad, 2009.

10 Calla, Alberto, 2009.

11 Silva, Jaime, 2009
}

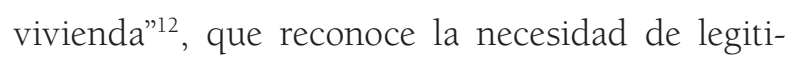
mar la efectiva participación de la población en la conformación de su propio hábitat. Sin que esto constituya una posición neoliberal para justificar que los gobiernos se desentiendan de la solución del problema social de la vivienda, es innegable el rol que puede jugar la población en la producción y transformación de su propio hábitat, sobre todo, cuando se parte de procesos planificados y asistidos como sería posible en el caso cubano.

Todo proceso sustentable ha de ser endógeno y por tanto, participativo ${ }^{13}$. La participación de la población en la conformación de su hábitat genera actitudes responsables y comprometidas que fomentan la identidad y el arraigo, con ventajas económicas, sociales y ambientales indiscutibles.

Sin embargo, los procesos participativos en la producción social del hábitat requieren de una adecuada gestión que favorezca la calidad integral de los resultados, tanto con respecto a la habitabilidad y la calidad de vida de la población, como en relación con el ambiente urbano. Para ello es necesario disponer de estructuras organizativas apropiadas que faciliten la gestión integral de la producción del hábitat a diferentes niveles.

12 Rodríguez Cáceres, Gustavo Marcelo, 2008.
13 González, Couret, Dania, 2003, p. 42. 
Por otro lado, el desarrollo local ha cobrado también cada vez más fuerza como complemento necesario del proceso de globalización ${ }^{14}$ y como principio esencial del desarrollo sustentable, al reducir la escala de manejo de los problemas y favorecer la participación y el desarrollo de procesos endógenos ${ }^{15}$. Por tanto, la dimensión habitacional debe ser también considerada en el Desarrollo Humano Local.

En Cuba la vivienda es considerada como un bien social y el estado mantiene aún la responsabilidad de facilitar el acceso de cada familia a una vivienda adecuada, para lo cual existe un Programa Constructivo $^{16}$ que no ha logrado satisfacer la demanda cualitativa y cuantitativa de la población. Pero la vivienda no es sólo un objeto a construir ${ }^{17}$, por tanto, es algo más que una cifra o una meta a cumplir o la decisión sobre materiales y tecnologías a ser empleados en su construcción.

La vivienda es el espacio vital de los seres humanos y la familia, con un impacto directo en la salud física y mental, es el barrio, la comunidad o la ciudad, con sus servicios e infraestructura y su tradición cultural, que condicionan la calidad de vida, la identidad y el

14 Rodríguez Maciá, Manuel, 2008.

15 González, Couret, Dania, 2000, p. 17-20.

16

El Programa Constructivo de la Vivienda en Cuba comprende tres procesos independientes: construcción por el estado de nuevas viviendas; conservación del fondo edificado por parte del estado, y la construcción y conservación de viviendas por esfuerzo propio de la población.

17 González, Couret, Dania, 2009

170 revista invi № 73 / Noviembre 2011 / Volumen N² 26: 167-198 arraigo. Es por ello que la actual Política de Vivienda en Cuba va encaminada hacia una mayor descentralización de los procesos y un incremento de la participación popular en la producción del hábitat.

El problema que la presente investigación resuelve es cómo gestionar el Programa de la Vivienda a escala local para mejorar la calidad del hábitat. El objetivo general del trabajo es precisamente demostrar que transformando los mecanismos de gestión, por ejemplo mediante la implementación de las Unidades Locales de Gestión de Hábitat (ULGH), es posible obtener resultados de mayor calidad. Para lograrlo se parte de la elaboración de un modelo teórico que toma como referencia la experiencia internacional, sobre cuya base se desarrolla un diagnóstico de la calidad del hábitat en la zona de estudio y su relación con el proceso de gestión, y se proponen soluciones. Finalmente, se evalúan los resultados de la implementación de este modelo de gestión durante dos años.

La experiencia aplicada en la ciudad de Ciego de Ávila, en la zona central del país, se encaminó a promover un proceso de gestión más integral y participativo 
del Programa de la Vivienda a nivel local, mediante la creación de Unidades Locales de Gestión, espacios físicos ubicados en el nivel más bajo de la estructura de gobierno en Cuba: el Consejo Popular.

La investigación ha sido realizada mediante tesis de maestría y doctorado y es parte del proyecto de investigación "Gestión participativa de la vivienda en Cuba", desarrollado entre 2008 y 2010, con financiamiento del Programa Ramal de Ciencia y Técnica del Ministerio de la Construcción dedicado a la vivienda.

\section{Métodos}

La investigación parte de la valoración de la experiencia nacional e internacional en materia de gestión de los procesos de producción social del hábitat, con vistas a identificar las mejores prácticas aplicables al caso de estudio y determinar las variables a considerar.

A los efectos de la presente investigación se asume como concepto de calidad en la vivienda el enunciado Aróztegui ${ }^{18}$ hace casi veinte años y que mantiene su vigencia. Así, la calidad de una vivienda es su aptitud para ser habitada con satisfacción de sus ocupantes. Este concepto ha sido incluso asumido por la Norma Cubana de "Requisitos funcionales y de habitabilidad en la vivienda" aprobada en $2008^{19}$.

18 Aróztegui, José Miguel, 1993.

19 NC 641, 2008.
El hábitat humano es mucho más que un techo, es un sistema de condiciones de vida materiales y espirituales, bióticas y abióticas, que envuelven, propician y determinan la existencia y convivencia saludable, en bienestar y en comunidad, de todos los miembros de la especie, al igual que su perfeccionamiento, multiplicación y perdurabilidad como ser social, tanto individual como colectivamente. Por tanto, el hábitat requiere de un enfoque más integral, de manera que se asume como calidad integral del hábitat su aptitud para propiciar una mejor calidad de vida para aquellos que lo disfrutan ${ }^{20}$.

El modelo teórico elaborado como base para la investigación clasifica las variables en independientes y dependientes, de acuerdo con los objetivos específicos del trabajo que consistían en diseñar un nuevo modelo de gestión y evaluar su impacto en la calidad del hábitat: las que caracterizan el proceso de gestión (independientes) y las que definen la calidad del hábitat (dependientes), a escala urbana y de la vivienda.

La primera versión de las variables objeto de estudio que partió de la revisión bibliográfica, fue sometida a consulta de expertos cubanos ${ }^{21}$, aplicando el método Delphis. Un resumen de la caracterización de los 16 expertos consultados, según su categoría, profesión, experiencia y ocupación, se muestra en la Tabla 1, y en la Tabla 2 se refleja la valoración de

20 Figueroa, Carlos y otros, 2007.

21 Águila Fleites, Odalia, 2010, p. 28. 
TABLA 1. CARACTERIZACIÓN DE LOS EXPERTOS CONSULTADOS PARA DETERMINAR LAS VARIABLES OBJETO DE ESTUDIO.

\begin{tabular}{llcc}
\hline CARACTERÍSTICAS & & \multicolumn{2}{c}{ CANTIDAD Y \% } \\
\hline \multirow{2}{*}{ Grado científico } & Doctores en ciencias técnicas & 8 & $50 \%$ \\
\hline \multirow{2}{*}{ Pategoría docente } & Profesores titulares & 5 & $31 \%$ \\
\cline { 2 - 4 } & Profesores auxiliares & 6 & $37 \%$ \\
\hline \multirow{2}{*}{ Años de experiencia en el tem } & Arquitectos & 12 & $75 \%$ \\
\cline { 2 - 4 } & Ingenieros & 2 & $12.5 \%$ \\
\cline { 2 - 4 } & Licenciados & 2 & $12.5 \%$ \\
\cline { 2 - 4 } & Más de 20 años vinculados al tema del hábitat 10 y 20 años vinculados al tema del hábitat & $63 \%$ \\
\cline { 2 - 4 } & Menos de 10 años vinculados al tema del hábitat & $25 \%$ \\
\hline \multirow{2}{*}{ Ocupación } & Trabajan en el Sistema de la Vivienda & 2 & $12 \%$ \\
\cline { 2 - 4 } & Trabajan en producción, docencia e investigación & 9 & $56 \%$ \\
\hline
\end{tabular}

FUENTE: Águila, 2010.

los expertos con respecto al grado de influencia de las variables de gestión en la calidad del hábitat.

Algunas de las variables identificadas como resultado de este proceso presentan particularidades en el caso de estudio:

- Marco legal: referido fundamentalmente a su flexibilidad para favorecer los procesos participativos y de gestión integral a nivel local.

- Prioridad: indica la prioridad otorgada al programa de la vivienda con respecto a otras es- feras como la salud y la educación, en cuanto a la asignación de recursos materiales y financieros. También se refiere a la prioridad otorgada a la nueva construcción en relación con la conservación de las viviendas existentes, o a la acción estatal con respecto a la participación de la población.

- Estructura institucional y organizativa: Refleja la estructura y funcionamiento del Programa de la Vivienda y su relación con las 
TABLA 2. INFLUENCIA DE LAS VARIABLES DE GESTIÓN EN LA CALIDAD DEL HÁBITAT, EN OPINIÓN DE LOS EXPERTOS CONSULTADOS.

\begin{tabular}{|c|c|c|c|c|}
\hline \multirow[t]{2}{*}{ VARIABLES DE GESTIÓN } & \multicolumn{4}{|c|}{$\begin{array}{l}\text { GRADO DE INFLUENCIA EN LA CALIDAD } \\
\text { DEL HÁBITAT }\end{array}$} \\
\hline & ALTO & MEDIO & BAJO & NINGUNO \\
\hline Marco legal & $44 \%$ & $56 \%$ & & \\
\hline Prioridad & $100 \%$ & & & \\
\hline Estructura y funcionamiento del Programa de la Vivienda & $94 \%$ & $6 \%$ & & \\
\hline Integración de actores & $82 \%$ & $6 \%$ & $6 \%$ & $6 \%$ \\
\hline Integralidad en las intervenciones & $94 \%$ & & & $6 \%$ \\
\hline Nivel de centralización & $75 \%$ & $25 \%$ & & \\
\hline Participación de la población & $13 \%$ & $38 \%$ & $43 \%$ & $6 \%$ \\
\hline No acceso a crédito y materiales & $6 \%$ & & & \\
\hline Inexistencia de asociaciones de constructores privados & $6 \%$ & & & \\
\hline Inexistencia de mercado legal de viviendas & $6 \%$ & & & \\
\hline No funcionamiento del PAC1 & $6 \%$ & & & \\
\hline Descontrol de proyectos y construcciones & $6 \%$ & & & \\
\hline Magnitud del déficit acumulado & $6 \%$ & & & \\
\hline Subdesarrollo de la industria de materiales & $6 \%$ & & & \\
\hline No uso de recursos locales & $6 \%$ & & & \\
\hline Poco poder económico de la mayoría de la población y el estado & $6 \%$ & & & \\
\hline Pobre calidad inicial de diseño y ejecución & $6 \%$ & & & \\
\hline Dificultades para el mantenimiento & $6 \%$ & & & \\
\hline Vulnerabilidad ante desastres & $6 \%$ & & & \\
\hline Malas condiciones bioclimáticas & $6 \%$ & & & \\
\hline Gestión urbana & $6 \%$ & & & \\
\hline Características de la población & $6 \%$ & & & \\
\hline
\end{tabular}

FUENTE: Águila, 2010 
instituciones del Sistema de la Vivienda ${ }^{22}$ y otros actores externos.

- Integración de actores: Caracteriza la relación entre los componentes del Sistema de la Vivienda, el rol del gobierno municipal y la Unidad Municipal Inversionista (UMIV) en la conducción del Programa de la Vivienda y en la integración de actores externos al sistema que también influyen en la producción de un hábitat integral, como la Dirección Municipal de Planificación Física (DMPF) y algunos organismos estatales que construyen viviendas.

- Integralidad de las intervenciones: se refiere a la integralidad de las actuaciones, tanto en lo urbano como en lo social, en sectores tipológicos o zonas homogéneas. Como objeto de estudio de esta investigación se identificaron zonas urbanas centrales y periféricas.

- Nivel de centralización: define el rol del estado en la toma de decisiones, así como la asignación de recursos para el Programa de la Vivienda y su gestión a nivel municipal.

- Participación de la población: valora el protagonismo de este actor en el proceso de producción del hábitat (planeamiento, diseño, ejecución, gestión, evaluación) y en la toma de decisiones.

Para identificar las variables que influyen en la calidad de la vivienda, también se partió de una consulta bibliográfica cuyo resumen aparece en la Tabla 3.

Los aspectos más recurrentes son necesidad de servicios básicos e infraestructura a escala urbana, y seguridad física, higiene y comodidad en la vivienda propiamente. No obstante, el equipo de trabajo en la investigación decidió incorporar también la presencia de espacios públicos y la relación con las regulaciones urbanas como garantía de la calidad del ambiente urbano, así como la satisfacción espiritual del habitante de manera general.

Las variables que influyen en la calidad del hábitat, tanto a escala urbana como de la vivienda, se estructuran para ser evaluadas según su impacto en el medio físico y en las personas, en cuyo caso se incluye la identidad de los habitantes con el lugar y su criterio con respecto al proceso de gestión, además de su satisfacción con la calidad de la vivienda y el ambiente urbano. Desde el punto de vista de una posible ponderación de las variables identificadas, todas se consideran significativas y se les asigna la misma importancia.

22 El Sistema de la Vivienda en Cuba desde el nivel provincial está integrado por las siguientes instituciones: Dirección Provincia de la Vivienda, Unidad Provincial Inversionista de la Vivienda, Entidad de Microbrigadas Sociales y Servicio a la Vivienda, y Programa de Arquitectos de la Comunidad. 
TABLA 3. VARIABLES OUE INFLUYEN EN LA CALIDAD DE LA VIVIENDA SEGÚN DIVERSAS FUENTES.

\begin{tabular}{|c|c|c|c|c|c|c|c|c|}
\hline $\begin{array}{l}\text { VARIABLES DE CALIDAD DE LA } \\
\text { VIVIENDA }\end{array}$ & $\begin{array}{l}\text { Tarchópulos } \\
\text { y Ceballos } \\
(2003)\end{array}$ & $\begin{array}{l}\text { Vivienda } \\
\text { Adecuada } \\
\text { (1996) }\end{array}$ & $\begin{array}{l}\text { Habitat } \\
\text { II } \\
(1996)\end{array}$ & $\begin{array}{l}\text { LRPVH } \\
\text { (1999) }\end{array}$ & $\begin{array}{l}\text { Núñez } \\
\text { (2006) }\end{array}$ & $\begin{array}{l}\text { González } \\
\text { (1997) }\end{array}$ & $\begin{array}{l}\text { NC } \\
641 \\
2008\end{array}$ & TOTAL \\
\hline Seguridad legal & & $\mathrm{X}$ & $\mathrm{X}$ & & & & & 2 \\
\hline Servicios básicos & $x$ & $X$ & $x$ & $\mathrm{X}$ & $\mathrm{X}$ & $\mathrm{X}$ & & 6 \\
\hline Infraestructura & $\mathrm{X}$ & & $X$ & $\mathrm{X}$ & $\mathrm{X}$ & $\mathrm{X}$ & & 5 \\
\hline Gastos soportables & & $\mathrm{X}$ & & & & & & 1 \\
\hline Habitabilidad & & $\mathrm{X}$ & & & & & & 1 \\
\hline Asequible & & $\mathrm{X}$ & $\mathrm{X}$ & & $\mathrm{X}$ & & & 3 \\
\hline Trabajo & & $\mathrm{X}$ & $\mathrm{X}$ & & & $\mathrm{X}$ & & 3 \\
\hline Identidad & & $\mathrm{X}$ & & & & & & 1 \\
\hline Privacidad & $\mathrm{X}$ & & $\mathrm{X}$ & & $\mathrm{X}$ & & $\mathrm{X}$ & 4 \\
\hline Confort. Comodidad & $\mathrm{X}$ & & $X$ & $x$ & $\mathrm{X}$ & $\mathrm{X}$ & $\mathrm{X}$ & 6 \\
\hline Seguridad física. Protección & $\mathrm{X}$ & & $X$ & $\bar{x}$ & $\mathrm{X}$ & $\mathrm{X}$ & $\mathrm{X}$ & 6 \\
\hline Estabilidad - Durabilidad & & & $\mathrm{X}$ & & & & $\mathrm{X}$ & 2 \\
\hline Saludable. Higiene & $\mathrm{X}$ & & $\mathrm{X}$ & $\mathrm{X}$ & $\mathrm{X}$ & $\mathrm{X}$ & $\mathrm{X}$ & 6 \\
\hline Costo razonable & & & $\mathrm{X}$ & & $\mathrm{x}$ & & & 2 \\
\hline Localización & $\mathrm{X}$ & & & $\mathrm{X}$ & & & & 2 \\
\hline Inserción en la trama urbana & & & & $\mathrm{X}$ & & & & 1 \\
\hline Flexibilidad & & & & $\mathrm{X}$ & & & & 1 \\
\hline Satisfacción espiritual & & & & & & $\mathrm{X}$ & & 1 \\
\hline Favorecer protección del medio & & & & & & $\mathrm{X}$ & & 1 \\
\hline $\begin{array}{l}\text { Uso Racional de Energía y } \\
\text { acondicionamiento térmico }\end{array}$ & & & & & & & $\mathrm{X}$ & 1 \\
\hline Relación con el exterior & & & & & & & $\mathrm{X}$ & 1 \\
\hline Espacios públicos & $\mathrm{X}$ & & & & & & & 1 \\
\hline
\end{tabular}

FUENTE: Águila, 2010 
TABLA 4. VARIABLES Y PARÁMETROS PARA EVALUAR LA CALIDAD DEL HÁBITAT A PARTIR DE SU IMPACTO EN EL MEDIO FÍsICO.

\begin{tabular}{|c|c|c|}
\hline GRUPO DE VARIABLES & VARIABLE & PARÁMETRO \\
\hline \multirow{18}{*}{$\begin{array}{l}\text { Calidad del ambiente } \\
\text { urbano }\end{array}$} & \multirow{5}{*}{ Espacios públicos } & Espacios verdes \\
\hline & & Parques \\
\hline & & Circulaciones peatonales \\
\hline & & Mobiliario urbano \\
\hline & & Jardinería y arbolado \\
\hline & \multirow{4}{*}{ Infraestructura técnica } & Abasto de agua \\
\hline & & Evacuación de residuales \\
\hline & & Alumbrado público \\
\hline & & Servicio telefónico \\
\hline & \multirow{3}{*}{ Servicios } & Recogida de residuales sólidos \\
\hline & & Mantenimiento de áreas verdes \\
\hline & & Limpieza de calles \\
\hline & \multirow{3}{*}{ Viales } & Pavimentación \\
\hline & & Vías peatonales \\
\hline & & Señalización \\
\hline & \multirow{2}{*}{ Regulaciones urbanas } & Cumplimiento de las regulaciones \\
\hline & & Integración con el entorno \\
\hline & Servicios básicos & Cumplimiento de la norma \\
\hline
\end{tabular}

FUENTE: Águila, 2010 


\begin{tabular}{lll} 
GRUPO DE VARIABLES & VARIABLE & PARÁMETRO \\
& Seguridad & $\frac{\text { Protección contra el medio exterior }}{\text { Constructiva }}$ \\
\cline { 2 - 3 } Calidad de la vivienda & Bienestar & $\frac{\text { Térmico }}{\text { Visual }}$ \\
\cline { 2 - 3 } & Salud & $\frac{\text { Aǵsico }}{\text { Iluminación natural }}$ \\
\cline { 2 - 3 } & $\frac{\text { Protección solar }}{\text { Ventilación natural }}$ \\
\hline & Satisfacción espiritual & $\frac{\text { Satisfacción espiritual }}{\text { Identidad }}$ \\
\hline
\end{tabular}

TABLA 5. VARIABLES Y PARÁMETROS PARA EVALUAR LA CALIDAD DEL HÁBITAT A PARTIR DE SU IMPACTO EN LAS PERSONAS.

\begin{tabular}{|c|c|c|}
\hline GRUPO DE VARIABLES & VARIABLE & PARÁMETRO \\
\hline \multirow{7}{*}{$\begin{array}{l}\text { Satisfacción con la } \\
\text { gestión }\end{array}$} & \multirow{2}{*}{ Estructura institucional y organizativa } & Formas organizativas \\
\hline & & Manejo de los recursos \\
\hline & \multirow{2}{*}{ Integración de actores } & Coordinación entre instituciones \\
\hline & & Coordinación con la población \\
\hline & \multirow{3}{*}{ Planeamiento de acciones integrales } & Zona central \\
\hline & & Periferia formal \\
\hline & & Periferia informal \\
\hline \multirow{6}{*}{ Identidad con el lugar } & \multirow{4}{*}{ Participación de la población } & Gestión \\
\hline & & Planeamiento \\
\hline & & Diseño \\
\hline & & Ejecución \\
\hline & \multirow{2}{*}{ Integralidad de las intervenciones } & A nivel urbano \\
\hline & & A nivel social \\
\hline
\end{tabular}

ARTíCULO: Unidades locales para la gestión integral del hábitat. Experiencia cubana revista invi № 73 / Noviembre 2011 / Volumen № 26: 167-198 177 Dania González Couret, Norberto Álvarez Pequeño, Odalia Águila Fleites y Deremis Pérez Aguilera 


\section{GRUPO DE VARIABLES VARIABLE}

\begin{tabular}{|c|c|c|}
\hline \multirow{18}{*}{$\begin{array}{l}\text { Satisfacción con la } \\
\text { calidad del ambiente } \\
\text { urbano }\end{array}$} & \multirow{5}{*}{ Espacios públicos } & \multirow{3}{*}{$\begin{array}{l}\text { Parques } \\
\text { Circulaciones peatonales }\end{array}$} \\
\hline & & \\
\hline & & \\
\hline & & Mobiliario urbano \\
\hline & & Jardinería y arbolado \\
\hline & \multirow{4}{*}{ Infraestructura técnica } & Abasto de agua \\
\hline & & Evacuación de residuales \\
\hline & & Alumbrado público \\
\hline & & Servicio telefónico \\
\hline & \multirow{3}{*}{ Servicios } & Recogida de residuales sólidos \\
\hline & & Mantenimiento de áreas verdes \\
\hline & & Limpieza de calles \\
\hline & \multirow{3}{*}{ Viales } & Pavimentación \\
\hline & & Vías peatonales \\
\hline & & Señalización \\
\hline & \multirow{2}{*}{ Regulaciones urbanas } & Cumplimiento de las regulaciones \\
\hline & & Integración con el entorno \\
\hline & Servicios básicos & Cumplimiento del plan urbano \\
\hline \multirow{13}{*}{$\begin{array}{l}\text { Satisfacción con la } \\
\text { calidad de la vivienda }\end{array}$} & \multirow{3}{*}{ Seguridad } & Protección contra el medio exterior \\
\hline & & Constructiva \\
\hline & & Legal \\
\hline & \multirow{3}{*}{ Bienestar } & Térmico \\
\hline & & Visual \\
\hline & & Físico \\
\hline & \multirow{4}{*}{ Salud } & Agua y saneamiento \\
\hline & & Iluminación natural \\
\hline & & Protección solar \\
\hline & & Ventilación natural \\
\hline & \multirow{3}{*}{ Satisfacción espiritual } & Satisfacción espiritual \\
\hline & & Identidad \\
\hline & & Expresión de personalidad y estatus \\
\hline
\end{tabular}

FUENTE: Águila, 2010

178 revista invi № 73 / Noviembre 2011 / Volumen № 26: 167-198

ARTíCULO: Unidades locales para la gestión integral del hábitat. Experiencia cubana Dania González Couret, Norberto Álvarez Pequeño, Odalia Águila Fleites y Deremis Pérez Aguilera 
En las Tablas 4 y 5 se muestran las variables y los parámetros considerados en la evaluación de cada una de ellas. El impacto en el medio físico se evalúa de forma objetiva a partir de la medición y la observación sobre la base de criterios técnicos que se comparan con indicadores de referencia, mientras que el impacto en las personas es una valoración subjetiva que refleja las opiniones expresadas por los habitantes con respecto a su grado de satisfacción en relación con la calidad del hábitat.

Sobre la base de las variables y parámetros identificados, se realizó un diagnóstico dirigido a evaluar la calidad del hábitat producido antes de la aplicación del nuevo modelo de gestión local diseñado como parte de la investigación, y se estableció la probable relación de los resultados con las variables definidas para caracterizar la gestión. Es decir, se identificaron los problemas de gestión que estaban afectando la calidad del hábitat desde el punto de vista de su impacto en el medio físico y en la satisfacción de las personas, a partir del criterio de 16 especialistas y directivos del sistema de la vivienda y otras instituciones del territorio como la Dirección de Planificación Física y la Empresa de Diseño. ${ }^{23}$

La gestión del Programa de la Vivienda en Cuba parte de una estructura centralizada que permite el manejo de los recursos disponibles a escala nacio-

23 Águila Fleites, Odalia, 2010, p. 52.

ARTÍCULO: Unidades locales para la gestión integral del hábitat. Experiencia cubana Dania González Couret, Norberto Álvarez Pequeño, Odalia Águila Fleites y Deremis Pérez Aguilera nal y hace posible el elevado subsidio que aún hoy prevalece para la vivienda de todos por igual, pero a la vez limita la iniciativa local para el desarrollo de mecanismos de gestión diferentes a los establecidos de manera general para todo el país. Por ello es posible identificar a nivel local aquellos aspectos del sistema de gestión centralizada que conspiran en contra de la calidad del hábitat en un sitio específico, incluso, por parte de los actores del sistema de la vivienda o la planificación física a esa escala.

Por otra parte, resulta imposible para la administración central hacer un diagnóstico objetivo de las carencias, por lo diverso de las condiciones específicas de cada lugar. Precisamente, el principal aporte del diagnóstico que se presenta en este trabajo radica en su carácter endógeno.

Este diagnóstico fue el punto de partida para la propuesta de un nuevo sistema de gestión integral del hábitat a nivel local. Teniendo en cuenta los problemas identificados y las mejores prácticas nacionales e internacionales, se definieron los principios sobre los cuales debería desarrollarse la gestión del hábitat en relación con las variables inicialmente identificadas. Eso condujo a la propuesta de las Unidades Locales de Gestión del Hábitat (ULGH) a escala del consejo popular, que constituye el nivel de base de la estructura de gobierno en $\mathrm{Cuba}^{24}$.

24 La circunscripción constituye un territorio delimitado con fines electorales, donde la población residente está representada por un delegado que forma parte del consejo popular.

revista invi № 73 / Noviembre 2011 / Volumen Nº 26: 167-198 179 
Esta propuesta parte de una idea inicial del sistema de gestión a nivel nacional, que fue la implementación del llamado "técnico integral del sistema de la vivienda" 25 , para atender los procesos derivados de la implementación del programa a escala local. Lo que se propone en esta ocasión es la inclusión de ese técnico integral dentro de una unidad de gestión local más abarcadora. Por tanto, la propuesta de la ULGH y la evaluación del impacto de su implementación en Ciego de Ávila constituyen una demostración de cómo puede mejorarse la implementación del proceso de gestión a escala local.

Así, la experiencia es perfectamente aplicable a nivel nacional, en cualquier unidad vecinal, barrio o área homogénea, según se requiera, independientemente de la correspondencia o no con las divisiones socio administrativas. También pudiera servir de referencia a nivel internacional, salvando las diferencias derivadas del modelo económico social. De hecho, guardan una estrecha relación con la experiencia colombiana de las Unidades Locales de Planificación Concertada (ULPC) ${ }^{26}$.

El nuevo modelo de gestión fue implementado en tres zonas urbanas seleccionadas como objeto de

25 Los técnicos integrales son profesionales (ingenieros civiles 0 arquitectos) o técnicos medios en construcción civil que trabajan en las unidades municipales inversionistas de la vivienda, a los cuales se les ha asignado la atención integral a todos los procesos inversionistas relacionados con el hábitat en una zona urbana específica.

Yory, Carlos Mario, 2005 estudio en la ciudad de Ciego de Ávila (Figura 1): un barrio del centro urbano tradicional de la ciudad; una zona de nuevo desarrollo en la periferia, planeada según el modelo de urbanización abierta del movimiento moderno, y un barrio también periférico pero con una urbanización tradicional (Figura 2).

La aplicación del modelo se produjo a partir del año 2007 y los resultados obtenidos con respecto a la calidad del hábitat fueron evaluados en 2010, teniendo en cuenta los indicadores definidos como referencia en la evaluación de cada parámetro, generalmente establecidos a partir de las normas y regulaciones vigentes en el país.

La información fue recopilada por los técnicos integrales en una ficha diagnóstico y mediante encuestas a la población, así como entrevistas a los principales actores involucrados. Los resultados de la evaluación que se presentan son producto de la elaboración colectiva de los actores involucrados mediante el desarrollo de dos talleres (diciembre de 2008 y octubre de 2009).

En la etapa intermedia del monitoreo de los resultados de la implementación del nuevo modelo de gestión (diciembre de 2008) se seleccionaron 
FIGURA 1. UBICACIÓN DE LA CIUDAD DE CIEGO DE ÁVILA EN LA ZONA CENTRAL DE CUBA.

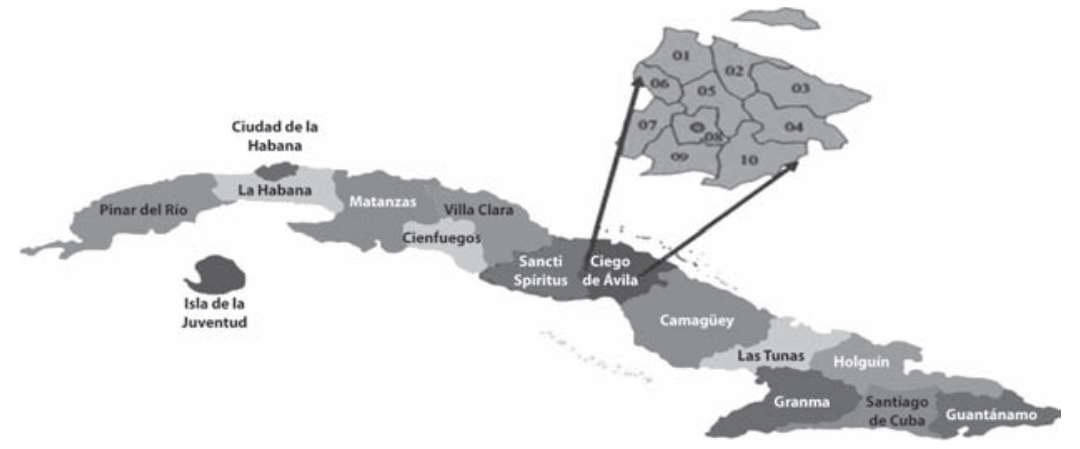

FUENTE: elaboración de los autores.

FIGURA 2. LOCALIZACIÓN DE LAS ZONAS URBANAS OBJETO DE ESTUDIO EN LA CIUDAD DE CIEGO DE ÁVILA.

FUENTE: Pérez, 2010

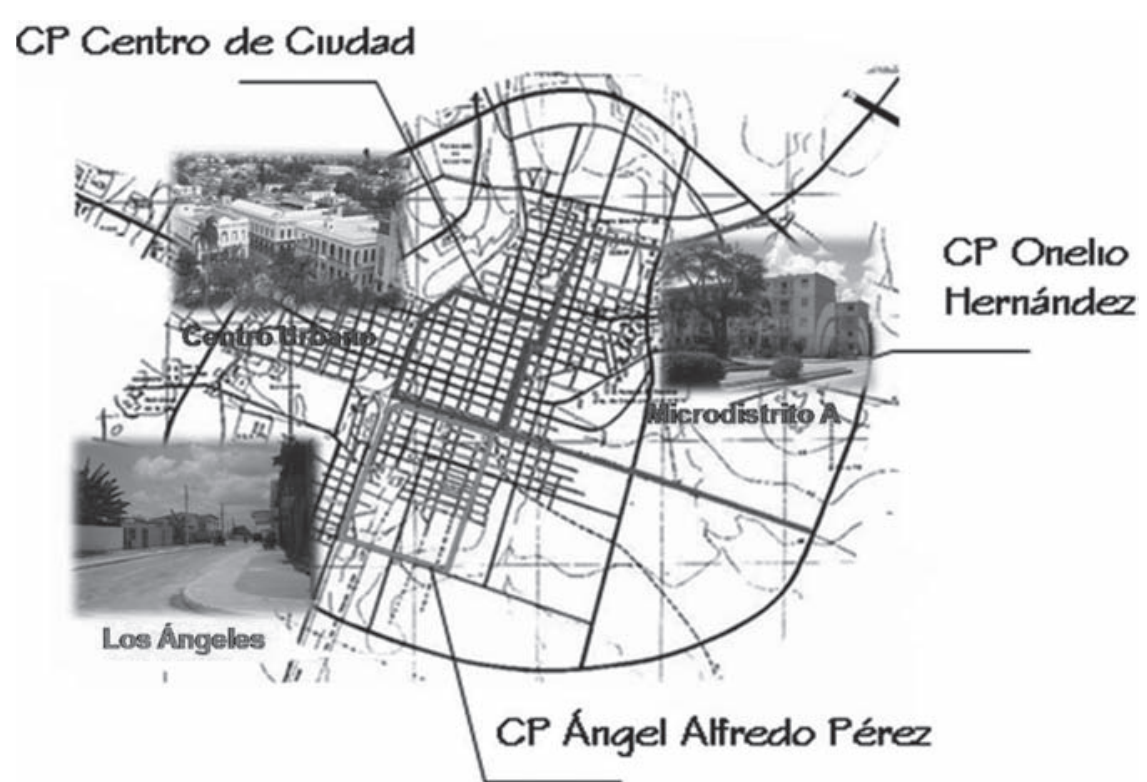

ARTíCULO: Unidades locales para la gestión integral del hábitat. Experiencia cubana Dania González Couret, Norberto Álvarez Pequeño, Odalia Águila Fleites y Deremis revista invi № 73 / Noviembre 2011 / Volumen № 26: 167-198 181 Pérez Aguilera 
de forma aleatoria 50 habitantes de cada consejo popular objeto de estudio, a los que se les aplicó una encuesta encaminada a saber el grado de conocimiento sobre la existencia de las Unidades Locales de Gestión del Hábitat y el técnico integral asignado a la zona, así como el vínculo establecido con ellos y los resultados obtenidos. En esa ocasión también fueron entrevistados cada uno de los presidentes de los 10 consejos populares que integran el municipio Ciego de Ávila, para recoger sus opiniones sobre las relaciones establecidas entre los actores del proceso, el flujo de información, la solución de los problemas del consejo popular y la evaluación del trabajo de la ULGH.

En la etapa final de evaluación de los resultados (octubre de 2009), se aplicaron encuestas a 363 personas proporcionalmente distribuidas entre las tres áreas seleccionadas como objeto de estudio. El criterio seguido fue recoger las opiniones del 50\% de las familias beneficiadas con las acciones constructivas desarrolladas y otro $10 \%$ de vecinos y visitantes del lugar, sobre las soluciones a los problemas detectados en el diagnóstico y su grado de satisfacción con éstas.

También en la etapa final de evaluación se recogieron, mediante entrevistas, las opiniones de 10 directivos y trabajadores del sistema de la vivienda en el municipio sobre el manejo de los recursos según el nuevo modelo, el trabajo por proyectos y la evaluación general del trabajo de las ULGH. Como podrá apreciarse, se trata de una evaluación inte- gral desde una perspectiva interdisciplinaria, resultado de las discusiones realizadas en los talleres al concluir cada una de las dos etapas del monitoreo.

\section{Resultados}

\section{DIAGNÓSTICO DE LA GESTIÓN DEL PROGRAMA DE LA VIVIENDA EN EL MUNICIPIO CIEGO DE ÁVILA}

El Programa de la Vivienda en Cuba es gestionado por el Sistema de la Vivienda que dirige el Instituto Nacional de la Vivienda, a través de las Direcciones de Vivienda y las Unidades Inversionistas en los niveles provincial y municipal, al cual se suma el Programa del Arquitecto de la Comunidad. El programa se desarrolla a partir de los planes, presupuestos y recursos asignados centralmente para determinados fines, que generalmente constituyen acciones dispersas en el territorio, de manera que no permiten obtener resultados integrales a nivel local.

El acceso de la población a los recursos para construir o mantener su vivienda no depende de su poder adquisitivo, sino de la disponibilidad de recursos asignados, que resultan subsidiados por el estado. Es por ello que en el caso cubano el nivel de ingresos de la población objeto de estudio expresado, por ejemplo mediante indicadores como el salario mínimo, no constituye un elemento de referencia para medir la accesibilidad a la vivienda de determinado sector. 
El estado financia la infraestructura, vialidad, servicios y espacios públicos, e incluso, las terminaciones y pinturas exteriores de los edificios. Los habitantes adquieren a precios subsidiados los recursos para las acciones constructivas a realizar en el interior de sus viviendas, cuando estos están disponibles porque son asignados por los programas estatales.

El municipio Ciego de Ávila, ubicado en la provincia del mismo nombre y donde se encuentra la ciudad cabecera, posee una extensión territorial de $436 \mathrm{~km}^{2}$ y una población de 148.915 habitantes que habitan en 51.795 viviendas. Cuenta con diez consejos populares, de los cuales siete son urbanos y en ellos se agrupan 73 circunscripciones.

Entre los principales problemas detectados, por los cuales el programa no ha logrado resolver el déficit cuantitativo ${ }^{27}$ y cualitativo (Tabla 6) de viviendas ni permitido obtener resultados de actuaciones integrales, puede citarse el hecho de que las decisiones se toman sobre la base de diagnósticos globales que no siempre se corresponden con las realidades específicas a nivel local y que conducen a la elaboración de planes cuantitativos donde las viviendas a construir se convierten en una ciframeta a alcanzar. Por otra parte, tanto la estructura del sistema de la vivienda como el programa sepa-

27 Considerando la relación entre el fondo útil de viviendas (37623) y la cantidad de núcleos económicos se obtiene un índice de satisfacción de la demanda de 0.85 (Águila Fleites, Odalia, 2010, p. 57) ran la gestión de las nuevas viviendas a ejecutar de la conservación de las existentes, y la acción estatal de la autoconstrucción, lo cual dificulta el logro de enfoques integrales y por tanto, resultados que redunden en una mayor calidad del hábitat.

Según el criterio de los expertos consultados para la realización del diagnóstico, los principales impactos negativos de la gestión del programa de la vivienda en la calidad del hábitat en el municipio se reflejan en la imagen y el ambiente urbano, seguidos de la calidad de ejecución de las viviendas, todo lo cual afecta la satisfacción de la población.

Las variables de la gestión que más influyen en estos resultados son la falta de integralidad en las intervenciones; la prioridad real otorgada al programa de la vivienda para la asignación de recursos con respecto a otros programas sociales como la salud y la educación; el marco legal que dificulta la participación de la población en el mejoramiento de su hábitat; la insuficiente integración entre los actores involucrados en el proceso de gestión; el nivel de centralización para la toma de decisiones respecto a los planes que se proponen, y también la estructura y funcionamiento del programa ${ }^{28}$

Por su parte, los expertos también opinaron que para obtener mejores resultados en la calidad del

28 Águila Fleites, Odalia, 2010, p. 72. 
TABLA 6. ESTADO TÉCNICO DE LAS VIVIENDAS EN CIEGO DE ÁVILA ANTES DE COMENZAR LA APLICACIÓN DEL NUEVO MODELO DE GESTIÓN.

\begin{tabular}{llllllll} 
Años & \multicolumn{2}{l}{ Estado técnico } & & & & Total \\
& Buenas & $\%$ & Regulares & $\%$ & Malas & $\%$ & 34424 \\
\hline 2005 & 22458 & 65 & 9432 & 27 & 2534 & 8 & 47592 \\
\hline 2006 & 34214 & 72 & 7253 & 15 & 6125 & 13 & 48908 \\
\hline 2007 & 36907 & 75 & 7292 & 15 & 4709 & 10 & 10 \\
\hline Promedio & & 71 & 19 & & & \\
\hline
\end{tabular}

FUENTE: Boletín Estadístico de la Unión Provincial Inversionista de la Vivienda, UPIV, 2008.

hábitat, la gestión del Programa de la Vivienda debería ser descentralizada hacia el nivel local, integral y participativa, para que tenga en cuenta las necesidades, expectativas y requerimientos de la población y otros actores locales.

\section{NUEVO MODELO DE GESTIÓN}

El nuevo modelo de gestión propuesto persigue transformar las variables de gestión identificadas en el marco teórico de la investigación sobre las cuales se puede actuar a escala local. Para ello, se establecieron los siguientes objetivos:

- Establecer las prioridades como resultado de diagnósticos locales a nivel del Consejo Popular, para concentrar las acciones en los lugares que más lo necesiten, de manera que se logren impactos favorables en la imagen urbana y se obtenga así una mayor satisfacción de la población.

- Modificar la estructura y funcionamiento de la Unidad Municipal Inversionista de la Vivienda, que es el principal actor de base del Programa de la Vivienda a nivel local, como vía para lograr una mayor descentralización y participación de la población, así como acciones integrales de mayor calidad a nivel urbano, al disponer de técnicos más capaces a nivel de base.

- Lograr la necesaria integración de actores a nivel local (Consejo Popular), tanto los del Sistema de la Vivienda como los externos. Esto además, facilita los trámites que la población debe realizar para la legalización de los procesos de autoconstrucción y la adquisición de los recursos necesarios. 
- Trabajar por programas y proyectos ${ }^{29}$ que permitan lograr la integralidad en las intervenciones, favoreciendo así la calidad del hábitat.

- Descentralizar la gestión del Programa de la Vivienda hacia el Consejo Popular mediante la creación de Unidades Locales de Gestión del Hábitat (ULGH).

- Promover la participación de la población no sólo en la ejecución de la vivienda, sino también en la toma de decisiones y la elaboración de los proyectos.

Un aporte esencial de la propuesta consiste en la descentralización de la gestión del Programa de la Vivienda hacia los consejos populares que constituyen el nivel más bajo de la estructura de gobierno en Cuba, creados a partir de 1990 en territorios homogéneos desde el punto de vista social y físico con vistas a agilizar la gestión de los servicios sociales, la cooperación entre entidades económicas y elevar el control popular sobre el funcionamiento de las actividades administrativas. Los consejos populares se subordinan a la Asamblea Municipal del Poder Popular y sus presidentes son miembros del Consejo de Administración Municipal, que tiene potestad legal para proponer y aprobar intervenciones a escala urbana.

Las Unidades Locales de Gestión del Hábitat (ULGH) constituyen la herramienta fundamen-

29 Álvarez pequeño, Norberto, 2003, pág. 27. tal del nuevo modelo, cuyos protagonistas son los técnicos integrales, y su implementación requiere una modificación en la estructura de las unidades inversionistas a nivel municipal y provincial que favorezca la integración.

En la Figura 3 se muestra la estructura de funcionamiento del nuevo modelo de gestión, donde el sistema de la vivienda a nivel municipal integrado por la Dirección Municipal de la Vivienda (DMV), la Empresa de Micro Brigada Social y Servicios a la Vivienda (EMBSSV), el Programa del Arquitecto de la Comunidad (PAC) y la Unidad Municipal Inversionista de la Vivienda (UMIV), se vinculan a través de esta última a la Unidad Local de Gestión del Hábitat en el Consejo Popular, que a su vez se relaciona a ese nivel con una unidad de venta de materiales en la EMBSSV, y con el Arquitecto de la Comunidad que es quien atiende a la población para la realización de los proyectos y otros servicios.

La ULGH se subordina al presidente del consejo popular y se relaciona con otros actores externos como las instituciones suministradoras y constructoras, y la oficina municipal de Planificación Física.

El número de técnicos integrales requerido en una ULGH varía en función de las características de cada consejo popular: extensión territorial, población, cantidad y calidad de las viviendas existentes, tipología habitacional y constructiva 


\section{FIGURA 3. ESTRUCTURA DE FUNCIONAMIENTO DEL NUEVO MODELO DE GESTIÓN.}

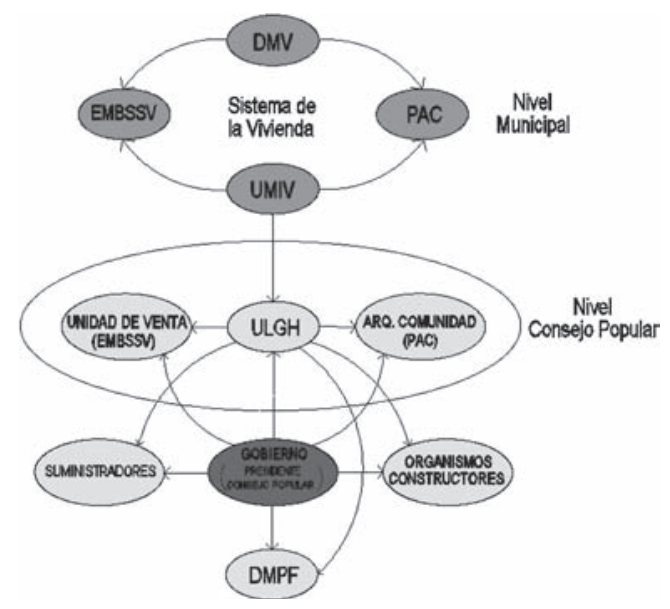

FUENTE: Águila, 2010

predominantes, entre otros aspectos. El técnico funciona como el inversionista integral del área de intervención dentro del consejo popular, ya sea una circunscripción, barrio, unidad vecinal o área homogénea ${ }^{30}$ y gestiona todos los procesos concebidos y aprobados en el plan de actuación correspondiente, tanto construcción de nuevas viviendas como rehabilitación de las existentes y el desarrollo de las urbanizaciones e infraestructura, a partir del diagnóstico realizado. Por supuesto estos técni-

30 En este caso se ha trabajado por áreas homogéneas, consideradas así a partir de sus características morfológicas.

186 revista invi № 73 / Noviembre 2011 / Volumen № 26: 167-198 cos han debido ser capacitados para garantizar un adecuado desempeño de sus funciones.

Los pasos a seguir por los técnicos integrales para la planificación, gestión, seguimiento y control de los procesos a ejecutar están recogidos en un manual de procedimientos de actuación que fue elaborado como parte del trabajo. Esta herramienta, a su vez, posibilita a las instancias superiores controlar y evaluar el funcionamiento de las ULGH.

Entre las funciones a desarrollar por las ULGH, a partir del trabajo de sus técnicos integrales, se encuentran:

- Elaboración de diagnósticos habitacionales detallados a nivel del consejo popular o el área de intervención a partir de la ficha de inventario establecida en la investigación ${ }^{31}$.

- Cálculo del déficit habitacional sobre la base de los datos reales obtenidos en los diagnósticos realizados.

- Caracterización y diagnóstico social de la comunidad.

- Identificación de líderes comunitarios que colaboren en la motivación de la población para la transformación esperada.

- Establecimiento de estrategias coordinadas y conjuntas con los factores de la comunidad

31 Pérez Aguilera, Deremis, 2010, p. 84.

ARTÍCULO: Unidades locales para la gestión integral del hábitat. Experiencia cubana Dania González Couret, Norberto Álvarez Pequeño, Odalia Águila Fleites y Deremis Pérez Aguilera 
para potenciar y motivar la participación de los pobladores en las actividades del ámbito comunitario y en la solución de sus problemas habitacionales.

- Establecimiento de prioridades, según problemática detectada en cada caso, para definir cuáles son las necesidades más acuciantes y las que generan mayores impactos en la calidad del hábitat a ese nivel local como construir y reponer viviendas; mejorar el fondo edificado y las condiciones precarias en cuarterías o barrios insalubres; reanimación urbana de ejes viales, accesos importantes a la ciudad o a los asentamientos.

- Propuesta de proyectos, planes y programas de actuación en correspondencia con la problemática detectada en los diagnósticos, tomando siempre en consideración los recursos disponibles y el impacto en el medio físico y en la satisfacción de las personas.

- Presentación de resultados de la propuesta de planes de actuación y proyectos al gobierno local y municipal, para su aprobación.

- Entrega de recursos materiales a la población o entidades patrocinadoras según prioridades establecidas ${ }^{32}$.

- Evaluación y seguimiento de las acciones que se ejecutan por los diferentes actores, control

32 Se refiere a los recursos subsidiados por el estado. de recursos financieros y materiales, revisión y ajustes de plazos, e inspecciones de calidad.

- Transparencia e información detallada y sistemática a todas las partes interesadas e involucradas.

\section{CASOS DE ESTUDIO}

Para la selección de los casos de estudio donde fueron evaluados los resultados de la implementación del nuevo modelo de gestión, se partió de los consejos populares donde el modelo se aplicó durante los años 2008 y 2009, de manera que se pudiera contar con resultados objetivos en el momento de hacer la evaluación a partir de las variables establecidas, y que se hubiesen ejecutado al menos el 50\% de las acciones de intervención y mejoramiento habitacional previstas.

A partir de estos criterios, se seleccionaron dentro de los diez Consejos Populares que conforman el municipio Ciego de Ávila, tres zonas urbanas ubicadas en el norte, centro y sur de la ciudad, en cada una de las cuales se aplicó el método de dirección por proyectos, que constituye una de las bases para el funcionamiento del nuevo modelo de gestión.

- Centro urbano. Abarca el centro histórico y tradicional de la ciudad, donde se concentra la mayor cantidad de servicios de nivel medio y superior, las principales edificaciones de

revista invi № 73 / Noviembre 2011 / Volumen № 26: 167-198 187 
valor histórico y arquitectónico y el 46\% de las cuarterías y ciudadelas ${ }^{33}$ del territorio. Los proyectos gestionados por las Unidades Locales de Gestión del Hábitat (ULGH) en esta zona incluyen la inserción de nuevas viviendas en lotes disponibles o en sustitución de edificaciones precarias sin valor histórico o patrimonial, manteniendo la coherencia del ambiente urbano a la vez que se mejora la calidad de vida de los residentes. También se desarrollan proyectos de rehabilitación y cualificación de fachadas en las vías principales para mejorar la imagen del centro histórico, así como recuperación de los corredores públicos típicos de esta ciudad, y acciones para mejorar la habitabilidad en ciudadelas y cuarterías.

- Barrios periféricos de urbanización abierta. Están constituidos por conjuntos habitacionales de edificios multifamiliares tipo bloques prefabricados repetitivos. La gestión de proyectos de las ULGH para estos barrios contempla el diagnóstico ambiental participativo a partir del cual se establecieron criterios de diseño y programas de actuación. También se realizaron proyectos de rehabilitación integral y de ambientación urbana, mediante la identificación de los edificios, complementada por un progra-

33 Se refiere a "casas de vecindad" proyectadas con tal fin o casas subdivididas, donde por lo general cada familia habita en un solo espacio.

188 revista invi № 73 / Noviembre 2011 / Volumen № 26: 167-198 ma de pintura que aplica una carta de colores recomendada en investigaciones precedentes ${ }^{34}$. Estos barrios fueron además incluidos en un programa de referencia nacional que contempla el mejoramiento de la imagen urbana de este tipo de conjuntos habitacionales.

- Barrios periféricos tradicionales. Se refiere a barrios periféricos de la ciudad, clasificados como insalubres por los problemas ambientales que presentan. En ellos se elaboraron diagnósticos detallados sobre cuya base se desarrollaron propuestas de mejoramiento mediante estrategias participativas, aprobadas, implementadas y monitoreadas a través del desarrollo de talleres.

\section{IMPLEMENTACIÓN DEL NUEVO MODELO DE GESTIÓN}

\section{Centro urbano (Calle Independencia).}

A partir de la decisión del gobierno de la ciudad de suprimir el tráfico vehicular en la principal arteria comercial (Calle Independencia) para transformarla en una calle peatonal, el Consejo Popular de esa zona urbana y la ULGH aprovecharon la oportunidad para incluir en el proyecto la rehabilitación de las viviendas existentes en las plantas altas de los comercios y servicios.

34 Martínez, José Antonio, 2005, p. 112. 
Así, se realizó la rehabilitación integral de 27 viviendas construidas en la primera mitad del siglo XX en esa calle principal de la ciudad, a las cuales se le repararon o repusieron los techos, según su estado técnico; se le sustituyeron las puertas, ventanas y paredes interiores en mal estado; se le repararon las cocinas y baños, y además se recuperaron elementos decorativos eclécticos deteriorados.

También se incluyeron en el proyecto de rehabilitación integral la reparación de las instalaciones hidrosanitarias en 91 apartamentos mediante la venta a la población de los accesorios necesarios a precios subsidiados. Fueron sustituidos los techos en mal estado de otras 9 viviendas y se pintaron las fachadas de 132 viviendas y 2 edificios multifamiliares existentes en la zona.

Con la ejecución del proyecto de renovación urbana en la calle peatonal, se favoreció la animación nocturna de esa zona central de la ciudad como lugar de esparcimiento y encuentro, y tanto los vecinos del lugar como los habitantes de la ciudad en general, se sienten más satisfechos con su entorno y con mayor sentido de pertenencia. La intervención incluyó el mejoramiento de la red de acueducto y alcantarillado, la ejecución de un parque infantil, la inclusión de nuevo equipamiento urbano y de baños públicos, inexistentes en el área, y la instalación de nuevos servicios por cambio de uso de locales con funciones incompatibles con este contexto urbano (Figuras 4 y 5 )
Por otra parte, la Unidad Provincial Inversionista de la Vivienda (UPIV) promovió la realización de concursos para el diseño de nuevos edificios de vivienda a construir en sustitución de edificaciones con alto grado de deterioro existentes en algunos lotes del centro urbano tradicional de la ciudad, para mejorar la imagen urbana mediante soluciones arquitectónicas integradas armónicamente al contexto. Con estas acciones, además, se aprovecha mejor el suelo y los servicios e instalaciones existentes en esa zona consolidada de la ciudad,

A solicitud de la ULGH, tres de estos proyectos se encuentran actualmente en ejecución y aportarán 60 nuevas viviendas, de las cuales 45 serán ocupadas por familias residentes en la zona, que participan activamente en la construcción de sus viviendas y que han sido actualmente reubicadas de forma temporal para facilitar el proceso de rehabilitación integral del centro urbano.

De este modo se abren nuevas posibilidades de preservación del centro histórico tradicional de la ciudad, y se demuestra que los métodos utilizados son apropiados para obtener diseños de alta calidad funcional y formal, ambientalmente válidos y constructivamente viables en las condiciones actuales, obteniéndose un mejoramiento de la calidad de vida de sus residentes que no sólo adquieren una vivienda decorosa sino que permanecen en su hábitat tradicional de alto valor urbano. 
FIGURA 4. LA CALLE INDEPENDENCIA EN EL CENTRO DE LA CIUDAD DE CIEGO DE ÁVILA, ANTES DE LA INTERVENCIÓN INTEGRAL.

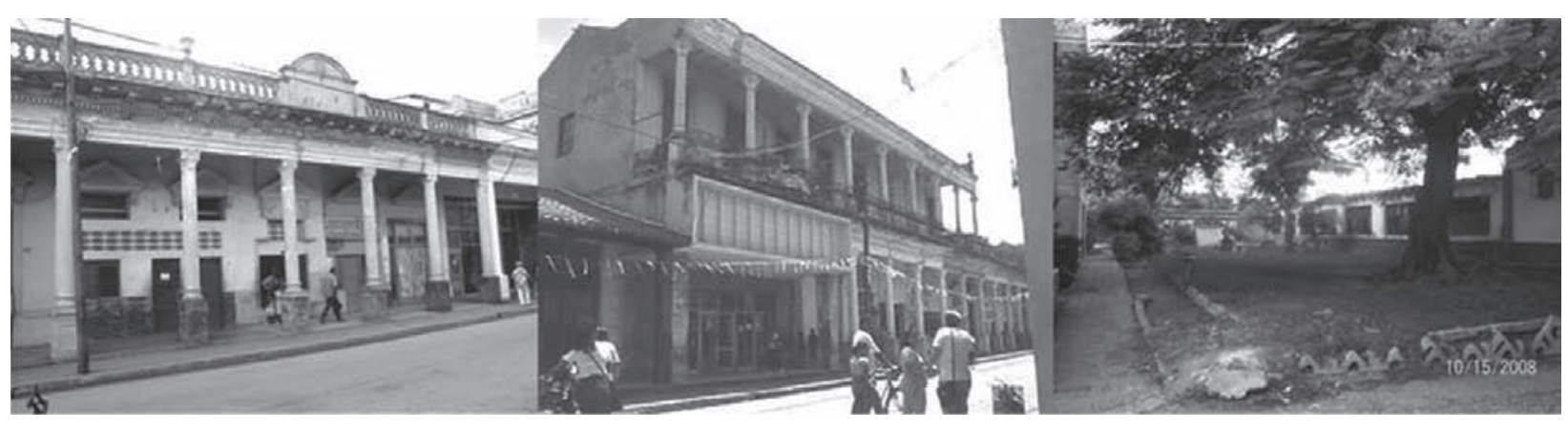

FUENTE: Pérez, 2010

FIGURA 5. LA CALLE INDEPENDENCIA EN EL CENTRO DE LA CIUDAD DE CIEGO DE ÁVILA, DESPUÉS DE LA INTERVENCIÓN INTEGRAL.

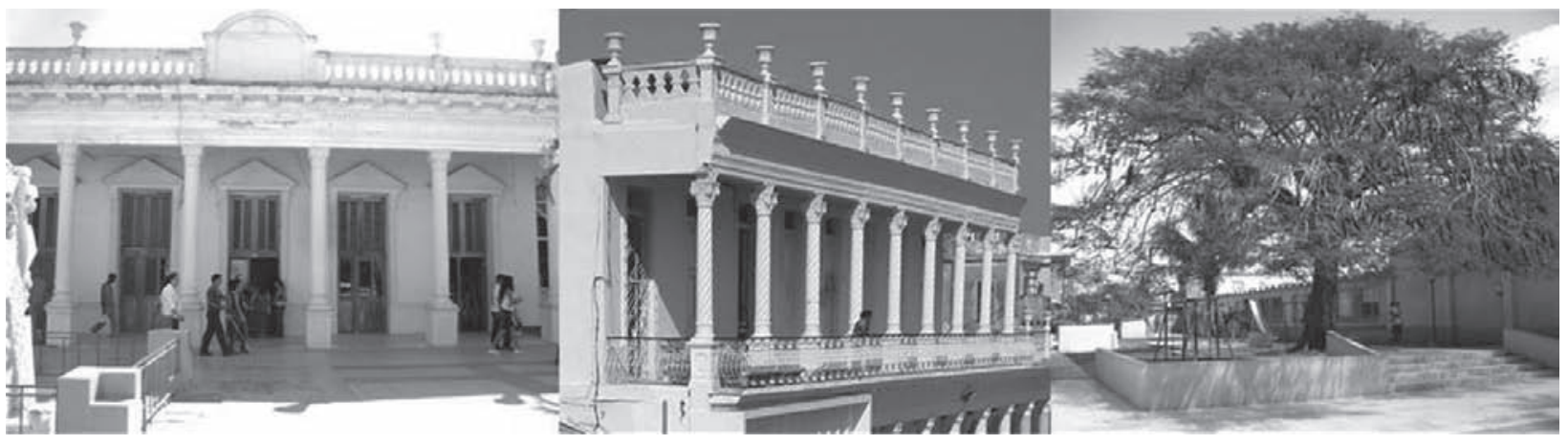

FUENTE: Pérez, 2010 
Como resultado de la aplicación del nuevo modelo de gestión integral del hábitat a nivel local se aprecia un balance positivo en el estado técnico de las viviendas en esta área urbana central de la ciudad y un mejoramiento en la calidad del ambiente urbano. (Figura 5).

\section{BaRRIOS PERIFÉRICOS DE URBANIZACIÓN ABIERTA (Microdistrito A)}

También en este caso, la ULGH del "Microdistrito A" de la ciudad aprovechó la oportunidad del Plan de Pintura propuesto a nivel municipal, para realizar otras acciones de conservación de los edificios a pintar, a partir del diagnóstico disponible, previamente realizado por los técnicos integrales de la unidad.

Entre las acciones realizadas en los apartamentos se encuentran la sustitución de puertas y ventanas, reparación de instalaciones y enchapes sanitarios en cocinas y baños, sustitución de barandas en escaleras y balcones e impermeabilización de cubiertas. En estas intervenciones fue involucrada la población como contribución al mantenimiento y cuidado posterior de las intervenciones ejecutadas, y también fueron convocados organismos y empresas radicadas en el territorio que apoyaron la realización de los trabajos de conservación a escala urbana.

Las intervenciones urbanas consistieron en la reparación de vías vehiculares y peatonales deterioradas, la rehabilitación de la red exterior de abasto de agua y evacuación de residuales en dos edificios multifamiliares y la instalación de 9 luminarias para mejorar el alumbrado público en los alrededores de los edificios, a los cuales se le adicionaron números de identificación como vía además para la reanimación urbana, y finalmente fueron pintadas todas las edificaciones de la zona según carta de colores propuesta para diferenciar los edificios, con vistas a mejorar la identidad de este conjunto habitacional donde prevalece la repetición y la monotonía.

Esta acción integral de conservación ha contribuido a mejorar la calidad de las viviendas y el ambiente urbano con la participación de la población que apoyó los trabajos realizados por los organismos y empresas del territorio. Así, los consejos de vecinos que no habían funcionado correctamente, se han sentido estimulados a velar por el cuidado y mantenimiento del entorno. (Figuras 6 y 7 ).

\section{Barrios periféricos tradicionales (Los Ángeles)}

El proyecto para el mejoramiento del barrio partió del diagnóstico previamente realizado por los técnicos integrales y para su implementación se definió un alcance en relación con la disponibilidad de recursos y se tuvo en cuenta la aprobación de las acciones propuestas por parte de los vecinos, el gobierno local y otros actores de la comunidad.

La intervención se realizó a partir de un programa concebido por etapas e incluyó la rehabilitación 
FIGURA 6. IMAGEN DEL MICRODISTRITO A EN LA CIUDAD DE CIEGO DE ÁVILA, ANTES DE LA IMPLEMENTACIÓN DEL NUEVO MODELO DE GESTIÓN INTEGRAL DEL HÁBITAT A NIVEL LOCAL.

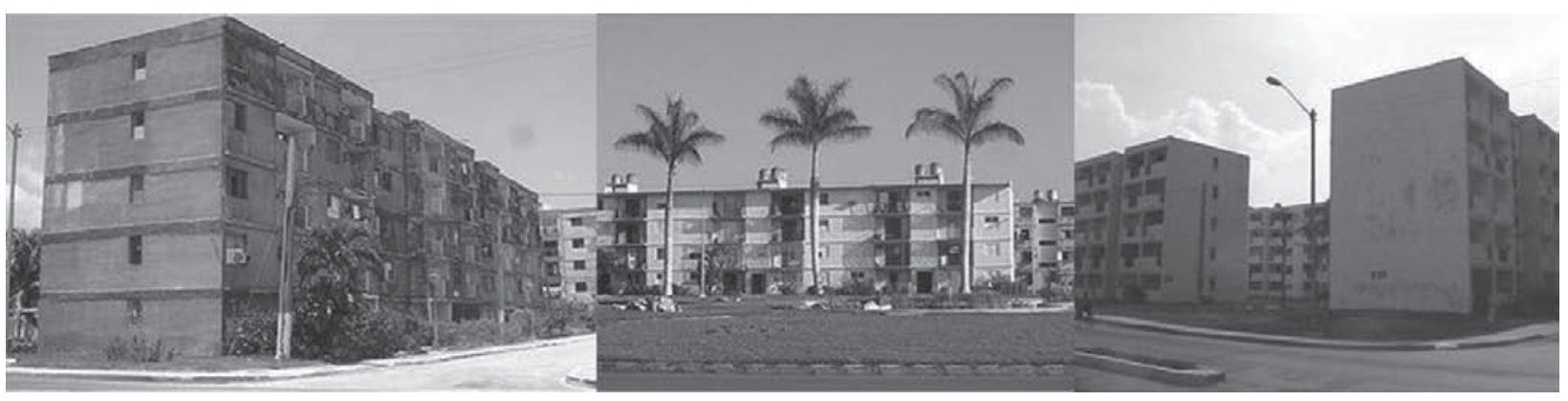

FUENTE: Pérez, 2010.

FIGURA 7. IMAGEN DEL MICRODISTRITO A EN LA CIUDAD DE CIEGO DE ÁVILA, DESPUÉS DE LA IMPLEMENTACIÓN DEL NUEVO MODELO DE GESTIÓN INTEGRAL DEL HÁBITAT A NIVEL LOCAL.

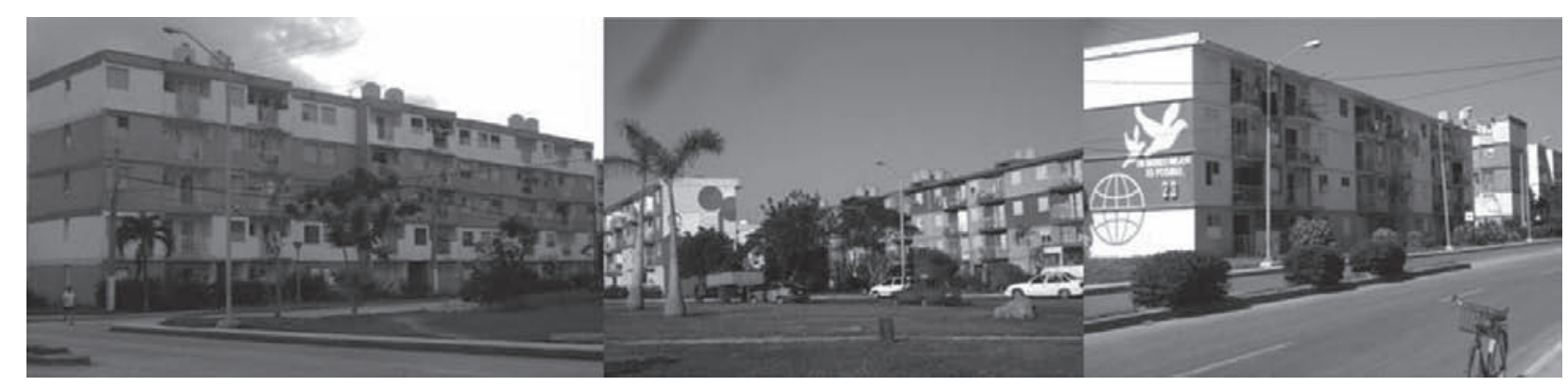

FUENTE: Pérez, 2010. 
de 46 viviendas que se encontraban en mal estado técnico, a las que les fue sustituida la cubierta, puertas, ventanas y elementos divisorios, y además, se repararon las cocinas. También se sustituyeron las cubiertas en mal estado de otras 21 viviendas, se repararon las instalaciones hidrosanitarias en 16 casos, se concluyó la ejecución de 5 nuevas viviendas que se encontraban en proceso de construcción y se pintaron otras 186.

Entre las acciones realizadas a escala urbana se encuentra la sustitución de las cercas perimetrales de 4 viviendas, originalmente realizadas de forma precaria con materiales de desecho; la pavimentación de vías peatonales y vehiculares que se encontraban sin terminar o en mal estado en 4 manzanas; la sustitución de la red hidráulica y sanitaria deteriorada, que permitió la conexión al alcantarillado de 33 viviendas y el abasto de agua a otras 9 que estaban servidas mediante pozos. Además, se colocaron 14 luminarias para el alumbrado público y se instaló un transformador que permitió sustituir 6 acometidas eléctricas informales.

Al igual que en los casos anteriores, se ha producido en este barrio una evolución favorable en la calidad de las viviendas y en el entorno urbano a partir de la aplicación del nuevo modelo para la gestión integral del hábitat a nivel local, que ofrece resultados que impactan positivamente en la imagen urbana y en la calidad del hábitat, lo cual se

ARTíCULO: Unidades locales para la gestión integral del hábitat. Experiencia cubana Dania González Couret, Norberto Álvarez Pequeño, Odalia Águila Fleites y Deremis Pérez Aguilera constata no sólo por el resultado en el medio físico, sino también en la satisfacción de los habitantes del lugar.

\section{EVALUACIÓN DEL IMPACTO DE LA APLICACIÓN DEL NUEVO MODELO DE GESTIÓN}

La metodología seguida para la evaluación del impacto de la aplicación del nuevo modelo de gestión en la calidad del hábitat ha sido expuesta. Como resultado de las encuestas aplicadas a 50 personas seleccionadas en cada una de las tres áreas de estudio en diciembre de 2008, se obtuvo que ya entonces la mayoría de los encuestados (78\%) conocían de la existencia de las ULGH y su localización en el barrio, y más de la mitad (59\%) sabían cuáles eran sus objetivos y conocían al técnico integral que atendía su circunscripción..$^{35}$

De los presidentes de los 10 consejos populares entrevistados, 9 confirmaron que a partir de la creación de las ULGH habían disminuido las quejas de la población sobre problemas relacionados con la vivienda, 8 opinaron que había una buena comunicación entre los actores involucrados en el mejoramiento habitacional a nivel local, y 7 consideraron buenos los resultados del trabajo de las ULGH.

En octubre de 2009 se discutieron los resultados de la información recopilada en los tres casos de estudio seleccionados, que sirvieron de base para

35 Pérez, 2010, p. 57. 
FIGURA 8. IMAGEN DEL BARRIO LOS ÁNGELES EN LA PERIFERIA, ANTES DE LA IMPLEMENTACIÓN DEL NUEVO MODELO DE GESTIÓN INTEGRAL DEL HÁBITAT A NIVEL LOCAL.

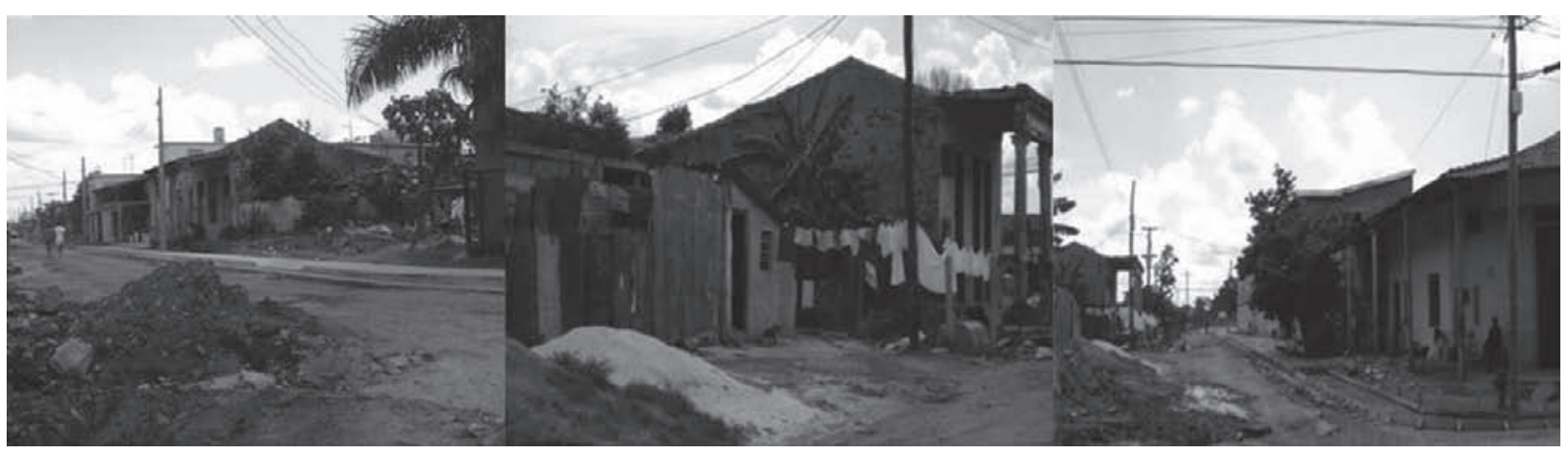

FUENTE: Pérez, 2010.

FIGURA 9. IMAGEN DEL BARRIO LOS ÁNGELES EN LA PERIFERIA, DESPUÉS DE LA IMPLEMENTACIÓN DEL NUEVO MODELO DE GESTIÓN INTEGRAL DEL HÁBITAT A NIVEL LOCAL.

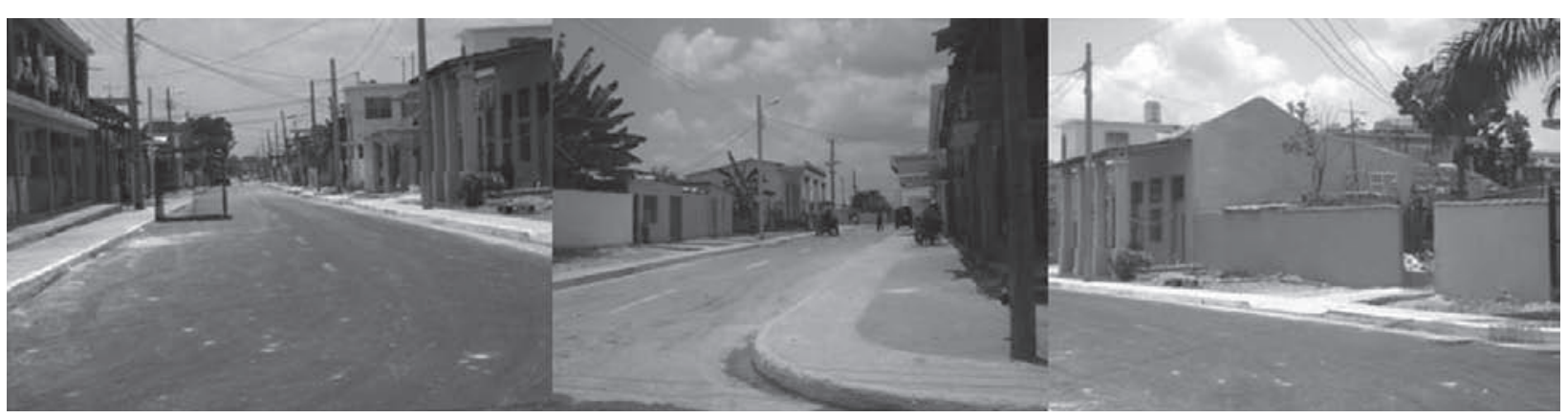

FUENTE: Pérez, 2010. 
la evaluación comparada del impacto, tanto en el medio físico como en la población, ocasionado por la aplicación del nuevo modelo para la gestión del hábitat a escala local.

Entre los aspectos más significativos discutidos en los talleres puede mencionarse la necesidad de continuar capacitando a los técnicos integrales para un mejor desempeño de sus funciones, la conveniencia de trabajar por proyectos (Dirección Integrada de Proyectos), la necesidad de mantener sistemáticamente una comisión encargada de aprobar los proyectos y velar por su calidad, fundamentalmente por la habitabilidad interior y la adecuada integración al contexto mediante el cumplimiento de las regulaciones urbanas.

El impacto en el medio físico es evidente y visible a partir de los datos cuantitativos ofrecidos que reflejan una mejoría en la calidad de las viviendas y en el entorno urbano. La satisfacción de los habitantes de las áreas urbanas objeto de estudio fue recogida mediante encuestas a 363 personas distribuidas proporcionalmente en los consejos populares estudiados.

A pasar de las diferencias entre las zonas urbanas monitoreadas de acuerdo con su centralidad y morfología, existe coincidencia en cuanto a las mejoras que han sido más frecuentemente reco- nocidas a escala urbana por parte de la población encuestada, que se refieren a las vías peatonales y vehiculares, la seguridad nocturna que se obtiene con el alumbrado público, y la disponibilidad de acueducto y alcantarillado.

La satisfacción de la población con respecto al mejoramiento de la infraestructura confirma su importancia en la calidad de vida. El nuevo modelo de gestión permite concentrar los recursos disponibles en acciones integrales locales a partir de diagnósticos específicos, respondiendo a las necesidades y prioridades particulares, para mejorar de manera general el ambiente urbano y con ello, la calidad de vida de la población. Esta forma de gestión local del hábitat contrarresta los mecanismos verticales especializados y sectoriales de la estructura y gestión centralizada y permite una mejor planificación del uso de los escasos recursos disponibles para lograr resultados de impacto en las comunidades.

Con respecto a la vivienda propiamente, lo que más se valora como resultado de las acciones de mejoramiento habitacional es la posibilidad de disponer de los espacios necesarios y la protección contra la lluvia.

El 85\% de la población encuestada opina que la calidad del lugar donde habita ha mejorado después de la intervención integral. 


\section{Conclusiones}

El nuevo modelo para la gestión integral del hábitat a nivel local ha sido implementado en tres contextos urbanos diferentes de la ciudad de Ciego de Ávila y se ha podido evaluar su impacto favorable, tanto en el medio físico como en la satisfacción de las personas.

Un aspecto esencial de este nuevo modelo ha sido la descentralización de la gestión del hábitat hacia el consejo popular, que es la estructura de base del sistema de gobierno en Cuba, lo cual ha favorecido la participación de la población en el proceso. La entidad que gestiona el programa a este nivel es la Unidad Local para la Gestión del Hábitat (ULGH), en la cual laboran tantos técnicos integrales como sea necesario en función de la extensión territorial, cantidad de población y complejidad del consejo popular. Cada técnico atiende un área urbana específica que puede coincidir con la estructura de la circunscripción electoral.

Desde la escala local del consejo popular no ha podido ser transformado el marco legal, identificado como una de las variables clave para la gestión integral del hábitat, pero sí la forma en que se deciden las prioridades para acometer las acciones constructivas a partir de diagnósticos locales específicos y teniendo en cuenta los recursos disponibles, sobre la base de la integralidad de las intervenciones y mediante el trabajo por proyec- tos, lo cual permite lograr resultados visibles en la mejoría de la calidad de las viviendas y del ambiente urbano, y con ello, en la calidad de vida de la población.

En esta experiencia también se ha modificado la estructura institucional y organizativa del sistema de la vivienda a escala municipal y provincial y se ha mejorado la interacción entre los diferentes actores a nivel local.

Con independencia de las particularidades de cada uno de los tres casos de estudio, las intervenciones integrales por proyectos han comprendido acciones a escala urbana y de las viviendas. La mejoría del ambiente urbano se logra mediante la ejecución y reparación de vías peatonales y vehiculares, infraestructura de acueducto y alcantarillado, alumbrado público y pintura de los edificios. A escala de las viviendas se reparan y sustituyen techos, puertas, ventanas, paredes divisorias e instalaciones hidrosanitarias.

La evaluación del impacto de la implementación del nuevo modelo de gestión en los barrios objeto de estudio se ha realizado a partir de la observación y la medición objetiva de los resultados y las opiniones de los diferentes actores involucrados, sobre la base de un sistema de variables, parámetros e indicadores identificados para evaluar la calidad del hábitat a escala urbana y de la vivienda. Estos resultados han sido elaborados de forma colectiva en talleres participativos, y también se ha 
tenido en cuenta el grado de satisfacción expresado por los propios habitantes.

El impacto favorable de la aplicación del nuevo modelo se aprecia de forma visible en la elevación de la calidad del ambiente urbano, en la satisfacción de la población y en el manifiesto incremento de la motivación en los habitantes para velar por el cuidado y mantenimiento del barrio.

\section{Bibliografía}

ÁGUILA FLEITES, Odalia. Nuevo modelo de gestión integral local del programa de la vivienda para mejorar la calidad del hábitat. Caso de estudio: Municipio Ciego de Ávila. La Habana, Facultad de Arquitectura, ISPJAE. 2010. Tesis para optar al grado de Máster en Vivienda Social.

ÁLVAREZ PEQUEÑO, Norberto. El enfoque de dirección integrada de proyectos aplicado al proceso inversionista de la vivienda. La Habana, Facultad de Arquitectura, ISPJAE. 2003. Tesis para optar al grado de Máster en Vivienda Social.

ARÓZTEGUI, José Miguel. Habitabilidad: aspectos técnicos. En: Anales del II Concurso iberoamericano de técnicas constructivas para viviendas de interés social. Montevideo, CYTED, Proyecto XIV-1. 1993. 2 t.

CALLA, Alberto. Política de vivienda en Bolivia. En: Conferencia Seminario Taller Internacional (2009, La Paz). La producción social de la vivienda y el hábitat en las políticas públicas. 2009.
CARTA mundial por el derecho a la ciudad. [En línea] En: ler concurso de ensayos sobre el derecho a la ciudad. La Paz, Red Hábitat. 2009, p.127-136. Disponible en: http://www.redmujer.org.ar/noticias/ Concurso_ensayos.pdf

FIGUEROA, Carlos y otros. Por una mejor gestión para resolver con efectividad el problema del hábitat en los asentamientos cubanos. Santa Clara, Departamento de Arquitectura, Facultad de Construcciones, Universidad Central de Las Villas. 2007.

GONZÁLEZ COURET, Dania. ¿Puede una ciudad ser sustentable? Revista Energía y Tú. (10): 17-20, 2000 .

GONZÁLEZ COURET, Dania. Economía y calidad en la vivienda. La Habana, Editorial Científico Técnica. 1997.

GONZÁLEZ COURET, Dania. La vivienda es algo más que un objeto a construir. Revista Temas. (58): 32 39, 2009.

GONZÁLEZ COURET, Dania. Vivienda y sustentabilidad urbana. Conceptos y propuestas. Revista Arquitectura y Urbanismo. 24(2): 34-42, 2003.

LEY de la República Popular de Venezuela del Hábitat. Caracas, [s.n.] 1999.

MARTÍNEZ MARTíNEZ, José Antonio. Guía para el diagnóstico ambiental de un microdistrito de viviendas. Criterios generales de diseño y programa de actuaciones. La Habana, Facultad de Arquitectura, ISPJAE. 2005. Tesis para optar al grado de Máster en Vivienda Social.

revista invi № 73 / Noviembre 2011 / Volumen № 26: 167-198 197 
NACIONES UNIDAS. Conferencia sobre los Asentamientos Humanos Hábitat II, declaración de Estambul sobre los asentamientos humanos. Estambul, ONU. 1996.

NC 641:2008. Edificaciones - Viviendas sociales urbanas - Requisitos funcionales y de habitabilidad. (Cuba, La Habana, S.N.) 2008.

NÚÑEZ, José Rafael. Condiciones precarias de hábitat y vivienda. Caracas, Fundación Escuela de Gerencia Social. 2006. 90 p.

PÉREZ AGUILERA, Deremis. Evaluación del nuevo modelo de gestión integral local del programa de la vivienda en Ciego de Ávila. La Habana, Facultad de Arquitectura, ISPJAE, 2010. Tesis para optar al grado de Máster en Vivienda Social.

PICHS MADRUGA, Ramón. Cambio climático, globalización y subdesarrollo. La Habana, Editorial Científico-Técnica. 2008. 160 p.

POR EL DERECHO HUMANO A LA VIVIENDA. La Paz, Red Hábitat. 2008. 28 p

198 revista invi № 73 / Noviembre 2011 / Volumen № 26: 167-198
RODRÍGUEZ CÁCERES, GUSTAVO MARCELO. La dimensión habitacional del desarrollo humano. Índice de desarrollo socio habitacional. La Paz, Red Hábitat. 2008. 133 p.

RODRÍGUEZ MACIÁ, MANUEL. La identidad desde lo local. Construcción de la cohesión social y territorial. San José de Costa Rica, Fundación DEMUCA. 2008. 82 p.

SILVA, Jaime. Política habitacional de Chile. En: Seminario Taller Internacional La Producción Social de la Vivienda y el Hábitat en las Políticas Públicas (La Paz, 2009). 2009

TARCHÓPULOS SIERRA, Doris. Calidad de la vivienda dirigida a los sectores de bajos ingresos en Bogotá. Bogotá, Centro Editorial Javeriano. 2003. 126 p.

YORY, Carlos Mario. Ciudad y Sustentabilidad II: componentes y contenido de un proyecto sustentable de ciudad a partir del concepto de topofilia. Bogotá, Universidad Piloto de Colombia. 2005. 169 p. ISBN 9589748880. 